Journal of Patient-Centered

Volume 3

Issue 4 -- Cardiovascular Aging

Article 24

$11-11-2016$

\title{
Evaluation of Patient Opinions and Experiences With Electronic Cigarettes at a Family Medicine Residency Clinic
}

Ima D. Tanner

Breana C. Cummens

Jessica J.F. Kram

Dennis J. Baumgardner

Follow this and additional works at: https://aah.org/jpcrr

Part of the Behavior and Behavior Mechanisms Commons, Community Health and Preventive Medicine Commons, Public Health Education and Promotion Commons, and the Substance Abuse and Addiction Commons

\section{Recommended Citation}

Tanner ID, Cummens BC, Kram JJ, Baumgardner DJ. Evaluation of patient opinions and experiences with electronic cigarettes at a family medicine residency clinic. J Patient Cent Res Rev. 2016;3:242.

Published quarterly by Midwest-based health system Advocate Aurora Health and indexed in PubMed Central, the Journal of Patient-Centered Research and Reviews (JPCRR) is an open access, peer-reviewed medical journal focused on disseminating scholarly works devoted to improving patient-centered care practices, health outcomes, and the patient experience. 
requirements as well as increased postoperative infection. More preoperative cryoprecipitate units, fewer postoperative cryoprecipitate units and more fresh frozen plasma units were independent predictors of infection.

\section{Effect of Code Status Handout on Resident Physician Comfort During the Admission Process}

Krystina Pischke, Jessica Schmid, Jessica J.F. Kram, Dennis J. Baumgardner

Department of Family Medicine, Aurora Health Care; Department of Family Medicine, Aurora UW Medical Group; Center for Urban Population Health

Background: Discussing code status can be a difficult part of the admission process, especially for residents. There have been various research studies looking at interventions to improve end-of-life discussions. However, these studies have focused on well-acquainted physicians and patients. With increasing use of hospitalists for inpatient care, there is increased need for improving code status discussions at admission.

Purpose: To determine if an easy-to-use handout would improve resident comfort with the code status discussion.

Methods: Following a literature search on how to discuss advance directives and end-of-life care, a code status handout was developed. The handout, written at fifth-grade reading level, was edited by attending physicians who oversaw the Adult Medicine Teaching Service (AMTS) at Aurora St. Luke's Medical Center, and used for patient admissions to AMTS by PGY1-3 residents from July 2015 to December 2015. A pre- and postintervention survey was emailed to residents before and after the start of their inpatient rotation, respectively. A predetermined script — read to residents on the first day of their rotation - discussed the handout, goals of the study and surveys. Paired t-tests were used to compare pre- and postintervention survey responses.

Results: Across respondents ( $\mathrm{N}=39)$, the majority were PGY1 $(63.2 \%)$ with prior personal experience explaining code status to patients $(73.7 \%)$. Pre- and postintervention surveys did not identify a difference in physician comfort level when explaining code status, even when compared to year in residency. On the postintervention survey, residents identified that the code status handout better informed patients $(73.0 \%)$, was easy to use $(75.0 \%)$ and that they would continue to use the handout to explain code status (78.4\%). Regarding "What would you change?" residents identified that the handout should be shorter (34.2\%).

Conclusion: Use of the handout did not show significant improvements to resident comfort in this small pilot. While residents identified that they would use the handout again, several remarked that the handout was too long for them or patients to read. Given that the handout was one page and in patient-friendly language, it is concerning that residents have such limited time for code status discussions. Future quality improvement studies should be conducted to standardize the code status discussion. Doing so will ensure that every patient is being properly educated on this important topic.
Evaluation of Patient Opinions and Experiences With Electronic Cigarettes at a Family Medicine Residency Clinic

Ima D. Tanner, Breana C. Cummens, Jessica J.F. Kram, Dennis J. Baumgardner

Department of Family Medicine, Aurora Health Care; Department of Family Medicine, Aurora UW Medical Group; Center for Urban Population Health

Background: Since 2003, electronic cigarettes (e-cigs) have grown in popularity. E-cigs are often marketed as a safer, healthier alternative to smoking traditional cigarettes or as an aid for smoking cessation. However, the risks and benefits of e-cig use, as well as the beliefs that influence use or avoidance, are poorly understood.

Purpose: To assess our patient population's perception or beliefs as they relate to e-cig use.

Methods: A 13-question survey regarding nicotine and e-cig use was distributed to English-speaking adult patients at Aurora St. Luke's Family Practice Clinic from August 2015 to January 2016. Questions assessed patient demographics and smoking history as well as knowledge and opinions of e-cigs. Descriptive statistics were used to describe patient characteristics. Associations between patient characteristics and beliefs were analyzed using chi-squared tests and Fisher's exact test, as appropriate. Significance was associated with $\mathrm{P}<0.05$.

Results: Across respondents $(\mathrm{N}=100)$, patients were more likely to be female $(60 \%)$ and of age $45-54$ years. Patients either had heard about e-cigs through advertisements $(48.9 \%)$ or by word of mouth $(36.9 \%)$. Many believed that e-cigs could help others quit smoking (47.6\%) and were a healthier smoking option over regular tobacco $(47.5 \%)$. Only $21.7 \%$ of patients had ever tried e-cigs. Age, sex and race/ethnicity were not associated with trying e-cigs. Those who identified as ever-smokers were more likely to have tried e-cigs than never-smokers $(\mathrm{P}=0.044)$. Additionally, current smokers were even more likely to have tried e-cigs than former or never smokers $(\mathrm{P}=0.017)$. Smoking status was not associated with education and race/ethnicity. Views regarding cost and whether e-cigs were a good choice for cessation also were not associated with smoking status.

Conclusion: Smoking status significantly affects whether a patient has tried e-cigs, with current smokers being most likely to have tried them. Demographic characteristics were not associated with use or opinions of e-cigs. Future studies should be done to assess use and attitudes in other clinic settings as well as use within our adolescent patient populations. 